\title{
Increased Epicardial Fat Tissue Is a Marker of Subclinic Atherosclerosis in Ankylosing Spondylitis
}

\author{
Nilgun ÜSTÜN, ${ }^{1}$ Mustafa KURT, ${ }^{2}$ Nesrin ATCI, ${ }^{3}$ Erman YAĞIZ,,${ }^{1}$ Hayal GÜLER, ${ }^{1}$ Ayşe TURHANOĞLU ${ }^{1}$ \\ ${ }^{1}$ Department of Physical Medicine and Rehabilitation, Medical Faculty of Mustafa Kemal University, Hatay, Turkey \\ ${ }^{2}$ Department of Cardiology, Medical Faculty of Mustafa Kemal University, Hatay, Turkey \\ ${ }^{3}$ Department of Radiology, Medical Faculty of Mustafa Kemal University, Hatay, Turkey
}

\begin{abstract}
Objectives: This study aims to assess subclinical atherosclerosis markers such as epicardial fat thickness, carotid intima media thickness (CIMT), and aortic stiffness index (ASI) in ankylosing spondylitis (AS) patients as well as to investigate the relationship between the subclinical atherosclerosis markers and disease activity/function/mobility indices.

Patients and methods: Twenty-six AS patients (22 males, 4 females; mean age 43 years) and 26 age- and sex-matched healthy controls ( 21 males, 5 females; mean age 43 years) were included. Patients and controls with any reported cardiovascular disease or other comorbidities were excluded. Disease activity, functional capacity and spinal mobility were measured using the Bath Ankylosing Spondylitis Disease Activity Index, Bath Ankylosing Spondylitis Functional Index, and Bath Ankylosing Spondylitis Metrology Index, respectively. All patients underwent complete transthoracic echocardiographic examination including epicardial fat thickness and ASI, and sonographic examination including CIMT.

Results: There were no significant differences in demographical and cardiovascular characteristics between AS patients and healthy controls ( $p>0.05)$. Epicardial fat thickness $(5.15 \pm 1.13$ vs. $4.11 \pm 1.22 ; p=0.003)$, CIMT $(0.70 \pm 0.16$ vs. $0.60 \pm 0.10 ; p=0.012)$ and $A S I(14.2 \pm 10.8$ vs. $8.6 \pm 3.1 ; p=0.018)$ were significantly increased in patients with AS compared to the healthy controls. There was no significant correlation between the subclinical atherosclerosis markers and disease activity/function/mobility indices $(p>0.05)$.
\end{abstract}

Conclusion: A significantly increased epicardial fat thickness, CIMT, and ASI were observed in AS patients compared with healthy controls.

Key words: Ankylosing spondylitis; atherosclerosis; epicardial fat tissue.

Ankylosing spondylitis (AS) is a chronic inflammatory disease characterized by axial skeleton and extra-articular involvement. ${ }^{1}$ Increased cardiovascular disease has been detected in AS patients compared to healthy controls. ${ }^{2}$

Atherosclerosis is one of the most important and common causes of mortality and morbidity throughout the world. It is also a well-known fact that atherosclerosis is a chronic, progressive and inflammatory disease with a long asymptomatic phase. Atherosclerosis has two phases: preclinical (subclinical) and clinical. Subclinical atherosclerosis refers to the early stage of the atherosclerotic disease which confers an increased risk of cardiovascular disease. This subclinical form may eventually lead to coronary artery disease, myocardial infarction, and sudden cardiac death. As early diagnosis is very important, a variety of imaging modalities including epicardial fat thickness, carotid intima media thickness (CIMT), and aortic stiffness index have been used to assess subclinical atherosclerosis. ${ }^{3,4}$

Epicardial fat tissue (EFT) is a component of visceral fat tissue located around the heart between myocardial and visceral epicardium. This metabolically active fat tissue releases various proinflammatory and proatherogenic cytokines. ${ }^{5}$ Epicardial fat tissue is a stronger risk factor for coronary artery disease compared with fat tissues located in other parts of the body, and EFT may have an important role in the development of coronary artery disease. ${ }^{6,7}$ Carotid intima-media 
thickness is an established risk marker of subclinical atherosclerosis in carotid arteries. ${ }^{8}$ The CIMT is strongly correlated with the presence of coronary artery diseases. ${ }^{9,10}$ Arterial stiffness index (ASI) is a marker for vascular dysfunction and an independent risk factor for cardiovascular disease. ${ }^{11}$ Several studies showed that patients with AS exhibited greater CIMT. ${ }^{12-14}$ and $\mathrm{ASI}^{15-18}$ than healthy controls. However, no studies have been performed regarding the association between AS patients and EFT.

The aim of the present study was to assess subclinical atherosclerosis markers such as EFT, CIMT and ASI in the AS patients as well as to investigate the relationship between the subclinical atherosclerosis markers and disease activity/function/mobility indices.

\section{PATIENTS AND METHODS}

We studied 26 consecutive patients with AS (22 males, 4 females; mean age 43 years) who were referred from our Physical Medicine and Rehabilitation Clinic of Mustafa Kemal University Hospital between 2012 and 2013, and 26 healthy controls who were matched for age, sex and body mass index. All patients met the modified New York diagnostic criteria. ${ }^{19}$ Patients and controls with any reported cardiovascular disease (coronary artery disease, heart failure, myocardial infarction, stroke, transient ischemic attack, and peripheral artery disease) were excluded. The patients with other comorbidities (diabetes mellitus, hypertension, hyperlipidemia, chronic kidney disease, and chronic hepatic disease) were also excluded. The study was approved by the local Ethics Committee of the University Hospital, and all subjects gave written informed consent.

Disease activity was measured using the Bath Ankylosing Spondylitis Disease Activity Index (BASDAI) $(0=$ no activity and $10=$ highest activity). ${ }^{20}$ The BASDAI includes six patientreported items of back pain, fatigue, peripheral joint pain and swelling, localized tenderness, and the duration and severity of morning stiffness. Functional capacity was measured using the Bath Ankylosing Spondylitis Functional Index (BASFI) $(0=$ lowest function and $10=$ highest function $){ }^{21}$ The BASFI contains 10 questions concerning activities of daily living. Spinal mobility was evaluated by the Bath Ankylosing Spondylitis Metrology Index (BASMI) $(0=$ lowest limitation and $10=$ highest limitation). ${ }^{22}$ The BASMI is a composite score based on five direct measurements of spinal mobility: lateral lumbar flexion, tragusto-wall distance, lumbar flexion, intermalleolar distance, and cervical rotation angle. ${ }^{22}$

All patients underwent complete transthoracic echocardiographic examination including EFT and ASI using GE Vivid 7 system with a $3.5 \mathrm{MHz}$ transducer (GE Vingmed Ultrasound AS, Horten, Norway), and sonographic examination including CIMT using high-resolution B-mode ultrasound with an electric linear transducer (mid-frequency $7.5 \mathrm{MHz}$ ) (Sonos 5500; Hewlett-Packard, Soma Technology Inc., CT, USA). To avoid interobserver variability, all echocardiographic measurements were performed by a cardiologist who had substantial specialty in echocardiography, and was unaware of the clinical characteristics of the subjects. All sonographic measurements were performed by an experienced radiologist, who was unaware of the clinical characteristics of the subjects.

Epicardial fat thickness was measured on the free wall of the right ventricle from the parasternal long-axis view. Epicardial fat thickness was described as an echo-free space in the pericardial layers, and its thickness was measured perpendicularly on the free wall of the right ventricle at end-systole for 3 to 10 cardiac cycles. To increase the confidence in the results, EFT measurement was performed at two different moments, and the percentage of $\mathrm{RR}$ interval ( $R$ wave to $R$ wave interval) with the least amount of motion was used.

Carotid intima media thickness was measured in the left and right common carotid arteries. During examination, the subject lay supine with the neck extended and the chin turned contralateral to the side. On a longitudinal, the anterior (near) and posterior (far) walls of the carotid artery are displayed as two bright white lines separated by a hypoechogenic space. The distance between the leading edge of the first bright line (the lumenintima interface) of the far wall and the leading edge of the second bright line (collagen-containing upper layer of tunica adventitia) indicates the IMT. ${ }^{23}$ Intima media thickness was measured at three points on the far walls of both the left 
and the right common carotid artery. The three locations were then averaged to produce the mean IMT for each side.

Aortic stiffness index was calculated from aortic diameters measured by echocardiography and blood pressures simultaneously measured by sphygmomanometry. Ascending aorta diameters were measured in the two dimensional (2D) parasternal long axis view at $3 \mathrm{~cm}$ above the aortic valve. The systolic diameter was measured at the maximal anterior motion of the aorta, whereas the diastolic diameter was measured at the peak of the QRS complex shown in the simultaneously recorded electrocardiogram. The formulas used in the calculation of aortic elasticity parameters were as follows: aortic strain $(\%)=$ (aortic systolic diameteraortic diastolic diameter) x 100/aortic diastolic diameter. $\mathrm{ASI}=$ (systolic blood pressure/diastolic blood pressure)/aortic strain.

\section{Statistical analysis}

Statistical analyses were performed using SPSS for Windows version 13.0 software program (SPSS Inc., Chicago, IL, USA). After certification of normal distribution, data were expressed in mean \pm standard deviation (SD); categorical variables were defined as percentage. Independent samples t-test or Mann-Whitney U test was used to compare the study variables between patients and healthy controls. For categorical variables, Chi-square test was used. Correlations between variables were tested by Pearson or Spearman correlation tests where appropriate. A $p$ value of $<0.05$ was considered statistically significant.

\section{RESULTS}

The demographic and cardiovascular characteristics of the 26 AS patients and 26 healthy controls are shown in Table 1. Mean disease duration was $11.83 \pm 10.98$ years. Mean BASDAI, BASFI and BASMI scores were $4.1 \pm 2$ (normal range 0-10), 4.2 \pm 2.1 (normal range 0-10), and 2.07 \pm 2.26 (normal range $0-10$ ), respectively. Four patients (15\%) were on tumor necrosis factor alpha antagonist, 22 patients $(75 \%)$ on disease modifying anti-rheumatic drug.

The characteristics of markers of subclinical atherosclerosis of the 26 AS patients and 26 healthy controls are also shown in Table 1. Epicardial fat thickness, CIMT and ASI were significantly higher in AS patients than in healthy controls $(p<0.05)$. There were no significant correlations between the EFT and CIMT $(r=0.162, p=0.429)$, and EFT and ASI $(r=0.308$, $\mathrm{p}=0.125$ ). However, there was significant positive correlation between the CIMT and ASI $(r=0.547$, $\mathrm{p}=0.004)$.

There were no significant correlations between the subclinical atherosclerosis markers with disease duration and disease activity/function/ mobility indices ( $p>0.05$; Table 2).

\section{DISCUSSION}

In this study, a significantly increased EFT, CIMT and ASI, markers of subclinical atherosclerosis, were observed in AS patients compared with healthy controls. To the best of our knowledge,

Table 1. Demographic and cardiovascular characteristics of patients and healthy controls

\begin{tabular}{|c|c|c|c|c|c|c|c|}
\hline & \multicolumn{3}{|c|}{ Controls $(n=26)$} & \multicolumn{3}{|c|}{ Patients $(n=26)$} & \multirow[b]{2}{*}{$p$} \\
\hline & $\mathrm{n}$ & $\%$ & Mean \pm SD & $\mathrm{n}$ & $\%$ & Mean \pm SD & \\
\hline Age (years) & & & $42.5 \pm 9.5$ & & & $43.7 \pm 11.8$ & 0.691 \\
\hline Male & 21 & 80.8 & & 22 & 84.6 & & 0.717 \\
\hline Body mass index $\left(\mathrm{kg} / \mathrm{m}^{2}\right)$ & & & $25.8 \pm 3.7$ & & & $28.1 \pm 5.3$ & 0.107 \\
\hline Smokers & 7 & 26.9 & & 8 & 30.8 & & 0.762 \\
\hline Systolic blood pressure (mmHg) & & & $116.0 \pm 9.9$ & & & $113.0 \pm 9.8$ & 0.244 \\
\hline Diastolic blood pressure (mmHg) & & & $74.0 \pm 6.0$ & & & $70.0 \pm 6.6$ & 0.076 \\
\hline Heart rate & & & $72.4 \pm 7.7$ & & & $73.1 \pm 13.1$ & 0.818 \\
\hline Epicardial fat tissue $(\mathrm{mm})$ & & & $4.1 \pm 1.2$ & & & $5.1 \pm 1.1$ & 0.003 \\
\hline Carotid intima-media thickness (mm) & & & $0.6 \pm 0.1$ & & & $0.7 \pm 0.1$ & 0.012 \\
\hline Aortic stiffness index & & & $8.6 \pm 3.1$ & & & $14.2 \pm 10.8$ & 0.018 \\
\hline
\end{tabular}


Table 2. Correlations of subclinical atherosclerosis markers with disease duration and clinical activity/function/mobility indices $(\mathrm{r} / \mathrm{p})$

\begin{tabular}{lccrr}
\hline & Disease duration & BASDAI & BASFI & BASMI \\
\hline Epicardial fat thickness & $-0.083 / 0.688$ & $-0.024 / 0.906$ & $0.010 / 0.998$ & $0.233 / 0.253$ \\
Carotid intima-media thickness & $0.075 / 0.715$ & $0.140 / 0.495$ & $0.193 / 0.346$ & $-0.024 / 0.906$ \\
Aortic stiffness index & $-0.210 / 0.302$ & $0.019 / 0.925$ & $0.017 / 0.933$ & $0.098 / 0.633$ \\
\hline BASDAI: Bath Ankylosing Spondylitis Disease Activity Index; BASFI: Bath Ankylosing Spondylitis Functional Index; BASMI: Bath Ankylosing Spondylitis Metrology Index.
\end{tabular}

this study is the first study investigating the EFT in the AS patients. In addition, we found no correlation between the subclinical atherosclerosis markers with disease duration and disease activity/function/mobility indices.

Adipose tissue has been acknowledged as an active endocrine organ having important effects on the vascular system. ${ }^{24}$ Visceral adipose tissue, a metabolically active endocrine and paracrine organ, secretes many proinflammatory and proatherogenic cytokines. ${ }^{25}$ Epicardial fat tissue, localized beneath the visceral pericardium, is more closely related to visceral fat rather than total body fat. ${ }^{25}$ Epicardial fat tissue is now recognized as a source of variable bioactive molecules ${ }^{5,25}$ which might affect the coronary artery. ${ }^{26,27}$ Our study results revealed that $A S$ patients had increased EFT when compared to the healthy controls.

An increased CIMT reflects the atherosclerotic burden and predicts the development of cardiovascular disease in the general population. ${ }^{28,29}$ In the present study, a higher CIMT was found in AS patients compared to healthy controls. This result is consistent with the data presented by several authors ${ }^{12-14}$ who demonstrated that AS patients, without risk factors for cardiovascular disease, had an increased CIMT compared to the healthy controls.

Differences in aortic elasticity have been reported to be independent predictors of worse outcome in cardiovascular diseases. ${ }^{30}$ The replacement of aortic elastic tissue by fibrosis constitutes the principal pathology in the deformation of aortic elasticity. In the present study, patients with AS had an increased ASI compared to the healthy controls. Several studies have demonstrated that patients with AS, without risk factors for cardiovascular disease, have increased aortic stiffness. ${ }^{15-18}$
In recent years, many efforts have been made to determine the causes of increased cardiovascular disease; traditional atherosclerotic risk factors, indeed, play a crucial role in the development, but do not fully explain the substantial burden of cardiovascular disease in AS. ${ }^{31}$ This suggests an unfavorable risk profile associated with AS related to systemic inflammation, which may predispose to cardiovascular disease. ${ }^{12}$ The present study included the AS patients -without clinically overt cardiovascular disease or comorbiditiesand healthy controls. There were no significant differences in demographic or cardiovascular characteristics between AS patients and healthy controls. The potential association between AS with increased EFT, CIMT and EFT may be related to persistent inflammation. ${ }^{32}$

Bülbül Sen et al. ${ }^{33}$ found that EFT significantly correlated with CIMT in the patients with psoriasis. In the present study, there was no significant correlation between EFT with CIMT and ASI. But there was significant positive correlation between the CIMT and ASI.

In the present study, there were no significant correlations between subclinical atherosclerosis markers and disease activity/function/mobility indices. This could be explained by use of drugs to control AS activity. Perrotta et al. ${ }^{14}$ also demonstrated no statistically significant correlation between CIMT and disease activity/function/ mobility indices in the patients with AS. Peters et al. ${ }^{18}$ also detected that CIMT did not show any association with BASDAI in AS patients. Angel et al. ${ }^{16}$ demonstrated that impairment in aortic elasticity occurs independently of disease activity in subjects with AS.

One of the major limitations of the present study was small sample size. The second limitation was the cross-sectional design of the study: the study groups were not under clinical follow-up. 
The lack of magnetic resonance imaging (the gold standard method for epicardial fat assessment) was the third limitation of our study. While magnetic resonance imaging and computed tomography readily evaluate EFT, these methods are not always easily accessible and applicable. Epicardial fat tissue measurement by echocardiography is an objective, noninvasive and readily available method, however, it has an inherent error when compared to computed tomography and magnetic resonance imaging.

In conclusion, this cross-sectional study has shown that a significantly increased EFT, CIMT and ASI, markers of subclinical atherosclerosis, may be observed in AS patients compared with healthy controls. In addition, we detected no associations between subclinical atherosclerosis markers and disease activity/functional/mobility indices.

\section{Declaration of conflicting interests}

The authors declared no conflicts of interest with respect to the authorship and/or publication of this article.

\section{Funding}

The authors received no financial support for the research and/or authorship of this article.

\section{REFERENCES}

1. Lautermann D, Braun J. Ankylosing spondylitis--cardiac manifestations. Clin Exp Rheumatol 2002;20:S11-5.

2. Han C, Robinson DW Jr, Hackett MV, Paramore LC, Fraeman KH, Bala MV. Cardiovascular disease and risk factors in patients with rheumatoid arthritis, psoriatic arthritis, and ankylosing spondylitis. J Rheumatol 2006;33:2167-72.

3. Lorenz MW, Markus HS, Bots ML, Rosvall M, Sitzer M. Prediction of clinical cardiovascular events with carotid intima-media thickness: a systematic review and meta-analysis. Circulation 2007;115:459-67.

4. Comert N, Yucel O, Ege MR, Yaylak B, Erdogan G, Yilmaz MB. Echocardiographic epicardial adipose tissue predicts subclinical atherosclerosis: epicardial adipose tissue and atherosclerosis. Angiology 2012;63:586-90.

5. Mazurek T, Zhang L, Zalewski A, Mannion JD, Diehl JT, Arafat $\mathrm{H}$, et al. Human epicardial adipose tissue is a source of inflammatory mediators. Circulation 2003;108:2460-6.

6. Taguchi R, Takasu J, Itani Y, Yamamoto R, Yokoyama $\mathrm{K}$, Watanabe $\mathrm{S}$, et al. Pericardial fat accumulation in men as a risk factor for coronary artery disease. Atherosclerosis 2001;157:203-9.

7. Gorter PM, de Vos AM, van der Graaf Y, Stella PR, Doevendans PA, Meijs MF, et al. Relation of epicardial and pericoronary fat to coronary atherosclerosis and coronary artery calcium in patients undergoing coronary angiography. Am J Cardiol 2008;102:380-5.

8. Wofford JL, Kahl FR, Howard GR, McKinney WM, Toole JF, Crouse JR 3rd. Relation of extent of extracranial carotid artery atherosclerosis as measured by B-mode ultrasound to the extent of coronary atherosclerosis. Arterioscler Thromb 1991;11:1786-94.

9. Lekakis JP, Papamichael CM, Cimponeriu AT, Stamatelopoulos KS, Papaioannou TG, Kanakakis $\mathrm{J}$, et al. Atherosclerotic changes of extracoronary arteries are associated with the extent of coronary atherosclerosis. Am J Cardiol 2000;85:949-52.

10. Simons PC, Algra A, Bots ML, Grobbee DE, van der Graaf Y. Common carotid intima-media thickness and arterial stiffness: indicators of cardiovascular risk in high-risk patients. The SMART Study (Second Manifestations of ARTerial disease). Circulation 1999;100:951-7.

11. Arnett DK, Evans GW, Riley WA. Arterial stiffness: a new cardiovascular risk factor? Am J Epidemiol 1994;140:669-82.

12. Mathieu S, Gossec L, Dougados M, Soubrier M. Cardiovascular profile in ankylosing spondylitis: a systematic review and meta-analysis. Arthritis Care Res (Hoboken) 2011 ;63:557-63.

13. Mathieu S, Joly H, Baron G, Tournadre A, Dubost JJ, Ristori JM, et al. Trend towards increased arterial stiffness or intima-media thickness in ankylosing spondylitis patients without clinically evident cardiovascular disease. Rheumatology (Oxford) 2008;47:1203-7.

14. Perrotta FM, Scarno A, Carboni A, Bernardo V, Montepaone M, Lubrano E, et al. Assessment of subclinical atherosclerosis in ankylosing spondylitis: correlations with disease activity indices. Reumatismo 2013;65:105-12.

15. Roldan CA, Chavez J, Wiest PW, Qualls CR, Crawford $\mathrm{MH}$. Aortic root disease and valve disease associated with ankylosing spondylitis. J Am Coll Cardiol 1998;32:1397-404.

16. Angel K, Provan SA, Gulseth HL, Mowinckel P, Kvien TK, Atar D. Tumor necrosis factor-alpha antagonists improve aortic stiffness in patients with inflammatory arthropathies: a controlled study. Hypertension 2010;55:333-8.

17. Moyssakis I, Gialafos E, Vassiliou VA, Boki K, Votteas $\mathrm{V}$, Sfikakis PP, et al. Myocardial performance and aortic elasticity are impaired in patients with ankylosing spondylitis. Scand J Rheumatol 2009;38:216-21.

18. Peters MJ, van Eijk IC, Smulders YM, Serne E, Dijkmans BA, van der Horst-Bruinsma IE, et al. Signs of accelerated preclinical atherosclerosis in patients with ankylosing spondylitis. J Rheumatol 2010;37:161-6. 
19. van der Linden S, Valkenburg HA, Cats A. Evaluation of diagnostic criteria for ankylosing spondylitis. A proposal for modification of the New York criteria. Arthritis Rheum 1984;27:361-8.

20. Garrett S, Jenkinson T, Kennedy LG, Whitelock H, Gaisford P, Calin A. A new approach to defining disease status in ankylosing spondylitis: the Bath Ankylosing Spondylitis Disease Activity Index. J Rheumatol 1994;21:2286-91.

21. Calin A, Garrett S, Whitelock H, Kennedy LG, O'Hea J, Mallorie P, et al. A new approach to defining functional ability in ankylosing spondylitis: the development of the Bath Ankylosing Spondylitis Functional Index. J Rheumatol 1994;21:2281-5.

22. Jenkinson TR, Mallorie PA, Whitelock HC, Kennedy LG, Garrett SL, Calin A. Defining spinal mobility in ankylosing spondylitis (AS). The Bath AS Metrology Index. J Rheumatol 1994;21:1694-8.

23. Iacobellis G, Assael F, Ribaudo MC, Zappaterreno A, Alessi G, Di Mario U, et al. Epicardial fat from echocardiography: a new method for visceral adipose tissue prediction. Obes Res 2003;11:304-10.

24. Marchington JM, Mattacks CA, Pond CM. Adipose tissue in the mammalian heart and pericardium: structure, foetal development and biochemical properties. Comp Biochem Physiol B 1989;94:225-32.

25. Iacobellis G, Pistilli D, Gucciardo M, Leonetti F, Miraldi F, Brancaccio G, et al. Adiponectin expression in human epicardial adipose tissue in vivo is lower in patients with coronary artery disease. Cytokine 2005;29:251-5.

26. Hirata Y, Kurobe H, Akaike M, Chikugo F, Hori T, Bando $\mathrm{Y}$, et al. Enhanced inflammation in epicardial fat in patients with coronary artery disease. Int Heart J 2011;52:139-42.

27. Hirata Y, Tabata M, Kurobe H, Motoki T, Akaike M, Nishio C, et al. Coronary atherosclerosis is associated with macrophage polarization in epicardial adipose tissue. J Am Coll Cardiol 2011;58:248-55.

28. Chambless LE, Heiss G, Folsom AR, Rosamond W, Szklo M, Sharrett AR, et al. Association of coronary heart disease incidence with carotid arterial wall thickness and major risk factors: the Atherosclerosis Risk in Communities (ARIC) Study,1987-1993. Am J Epidemiol 1997;146:483-94.

29. O'Leary DH, Polak JF, Kronmal RA, Manolio TA, Burke GL, Wolfson SK Jr. Carotid-artery intima and media thickness as a risk factor for myocardial infarction and stroke in older adults. Cardiovascular Health Study Collaborative Research Group. N Engl J Med 1999;340:14-22.

30. Sakuragi S, Iwasaki J, Tokunaga N, Hiramatsu S, Ohe T. Aortic stiffness is an independent predictor of left ventricular function in patients with coronary heart disease. Cardiology 2005;103:107-12.

31. Peters MJ, van der Horst-Bruinsma IE, Dijkmans BA, Nurmohamed MT. Cardiovascular risk profile of patients with spondylarthropathies, particularly ankylosing spondylitis and psoriatic arthritis. Semin Arthritis Rheum 2004;34:585-92.

32. Ross R. Atherosclerosis--an inflammatory disease. N Engl J Med 1999;340:115-26.

33. Bulbul Sen B, Atci N, Rifaioglu EN, Ekiz O, Kartal I, Buyukkaya $\mathrm{E}$, et al. Increased epicardial fat tissue is a marker of subclinical atherosclerosis in patients with psoriasis. Br J Dermatol 2013;169:1081-6. 